\title{
The effect of a prior presentation on temporal judgments in a perceptual identification task
}

\author{
DAWN WITHERSPOON and LORRAINE G. ALLAN \\ McMaster University, Hamilton, Ontario, Canada
}

\begin{abstract}
Subjects read aloud words presented once at the rate of one per second. A perceptual identification task, involving 30- or 50-msec presentations, followed. Some of the words presented for identification had been read previously; others were new. After each presentation, in addition to identifying the word, the subjects judged its duration. The data indicate that a single presentation of a word affects its later perception, as revealed by enhanced perceptual identification, longer duration judgments, and better temporal discrimination. A second experiment showed that a single presentation influenced duration judgments even when identification was not required. The final experiment addressed the issue of what is preserved in memory from a prior presentation. The results from the three experiments indicate that duration judgments provide a valuable dependent measure of memory in the perceptual identification task and support the misattribution hypothesis: A prior presentation enhances perceptual identification, and this increase in relative perceptual fluency is incorrectly attributed to a longer presentation duration.
\end{abstract}

Many who have traveled in a foreign country in which an unfamiliar language is spoken have commented that the native speakers seem to talk much faster than people back home. It is as though lack of familiarity with a language makes the words rush by, whereas familiarity makes the words hang in the air longer than they actually do. ${ }^{1}$ This subjective impression that familiarity affects judgments of duration has been supported experimentally as well. For example, Devane (1974), Warm, Greenberg, and Dube (1964), and Warm and McCray (1969) have reported that the durations of presentation of familiar words, as defined by frequency of usage in Thorndike and Lorge (1944), were judged to be longer than those of unfamiliar words in tachistoscopic identification tasks.

A number of studies (e.g., Feustel, Shiffrin, \& Salasoo, 1983; Jacoby, 1983a, 1983b, 1984; Jacoby \& Dallas, 1981; Jacoby \& Witherspoon, 1982; Morton, 1979; Murrell \& Morton, 1974; Witherspoon, 1983) have shown that one prior presentation of an item enhances subsequent perceptual identification under tachistoscopic conditions. In the experiments reported by Jacoby and Dallas (1981), the subjects first read aloud a list of words, each word being presented once on the screen at a rate of about one per second. A second list of words was then presented, each word now being shown for a brief constant duration of about $35 \mathrm{msec}$. The second (test) list contained some words from the original (study) list and also new words

This research was supported by a grant from the Natural Sciences and Engineering Research Council of Canada to L. Allan. Some of the data were presented at the 1983 meeting of The Psychonomic Society. The authors express their appreciation to $L$. L. Jacoby for the use of his equipment and for his valuable comments on earlier drafts of this paper. D. Witherspoon is now at the University of Toronto, Erindale Campus, Toronto, Ontario, Canada L5L 1C6. L. Allan is with the Department of Psychology, McMaster University, Hamilton, Ontario, Canada L8S 4KI. not presented during study. Jacoby and Dallas found that the probability of a correct identification of the briefly presented test words was higher for the words presented during study than for new words. Of particular interest to the present paper are the spontaneous reports by subjects that some words appeared to "jump out" from the screen, giving the impression of variable presentation durations, when in fact a constant duration was used. These spontaneous comments suggest that one prior presentation of a word may influence its judged duration.

Jacoby and Dallas (1981) introduced the concept of "relative perceptual fluency" in discussing perceptual enhancement resulting from a prior presentation. In commenting on the spontaneous reports that the presentation duration varied, they suggested that subjects may incorrectly attribute relative perceptual fluency to a longer presentation duration: the more fluent the perception, the longer the attributed presentation duration. In the experiments to be reported, we asked subjects to make duration judgments, as well as identifications. If relative perceptual fluency is misattributed to presentation duration, then one would expect previously presented words to be judged to be longer in duration than words not presented during study.

It is well documented in the time-perception literature that intervals with identical stimulus durations are not always judged to be equal in perceived duration. Rather, the temporal judgment is influenced by such nontemporal characteristics of the marker as its modality, nature (filled vs. empty), energy, and complexity (see Allan, 1979). Most relevant to the present research are the studies concerned with the influence of word familiarity on the judged duration of brief temporal intervals (e.g., Avant \& Lyman, 1975; Avant, Lyman, \& Antes, 1975; Devane, 1974; Thomas \& Weaver, 1975; Warm et al., 1964; 
Warm \& McCray, 1969). In those studies, familiarity was defined along a frequency-of-usage dimension or along a word-nonword dimension.

The relationship between judged duration and familiarity is of interest in the context of the argument put forth by Jacoby and Dallas (1981) and Witherspoon (1983), that relative perceptual fluency constitutes a feeling of familiarity that serves as one basis for recognition memory, that is, for distinguishing between old familiar items and new unfamiliar items. Since a previously presented word is more readily perceived, it is likely to be judged as having been seen before in the experiment. For these investigators, relative perceptual fluency is one basis for recognition performance, that is, for distinguishing between old familiar and new unfamiliar items.

In the experiments to be reported, we explored directly the effect of a nontemporal variable-namely, a prior presentation-on the judged duration of brief temporal intervals. The demonstration of a relationship between a prior presentation and judged duration is of theoretical importance. The effect of a prior presentation on perceptual identification is obviously produced by the subject's "remembering" the study words in some sense, although, as Jacoby and Witherspoon (1982) maintained, it may be independent of the subject's awareness that the word was presented previously. Judged duration might provide an additional, potentially sensitive, indicator of memory for a prior presentation.

The procedure used was similar to that employed by Jacoby (1983a, 1983b; Jacoby \& Dallas, 1981) in his perceptual identification studies, except that presentation duration was varied and, in addition to identifying the words, the subjects were required to make category judgments about the durations of the words. The category-judgment task allows the evaluation of the effect of a single presentation on judged duration as well as on duration discrimination. Judgments of duration provide information about perceived or apparent duration, whereas durationdiscrimination performance provides information about the ability to distinguish among a set of confusable durations (see Allan, 1979). As we mentioned previously, judged duration is very much influenced by the way in which the temporal interval is defined or marked. In contrast, many studies have reported no effect of these same variables on duration discrimination or on temporal resolution (see Allan, 1979). The category-judgment task allows us to study the effect of a prior presentation of a word on both judged duration and temporal resolution.

\section{EXPERIMENT $1^{2}$}

\section{Method}

\section{Subjects}

Twenty-one paid volunteers participated in this experiment: 10 Hamilton secondary school students and 11 McMaster University students. Due to the nature of the stimulus materials, all subjects (in Experiments 2 and 3 as well) were required to be native English speakers or to have spoken English fluently for at least 10 years.

\section{Materials and Apparatus}

A word pool of 134 five-letter nouns was selected from the lowfrequency category (fewer than 45 occurrences per million) in Thorndike and Lorge (1944). Fourteen of these words were used solely for practice (Phase 3 ). The remaining 120 words were randomly assigned to one of the three sets ( 40 words each), and the three sets were counterbalanced for item status: presented in study and test, presented only in study, presented only in test. All phases of the experiment were under the control of a PDP-8A computer. The $26.5 \times 18.5 \mathrm{~cm}$ video screen of this system was covered by a black construction-paper mask that contained an $8.5 \times 1.0 \mathrm{~cm}$ window. The stimulus material was presented in this window. All letters were uppercase. The subject sat in front of the computer screen at a distance of about 70 to $75 \mathrm{~cm}^{3}$

\section{Procedure}

The subjects were tested individually. A session lasted approximately $45 \mathrm{~min}$ and consisted of four phases. The subjects were told that the main objective of the experiment was to investigate speeded reading ability and that they would be required to read aloud words presented at different exposure durations. They were also told that, since speeded reading skills might involve temporal resolution, they would be required to make judgments about presentation duration. They were informed that there would be a number of phases and that the relevant instructions would precede each phase.

Phase 1: Study. A list of 80 words was constructed from two of the three sets of words. Each of the 80 words was presented once at the rate of one per second. The subjects were instructed to read each word aloud rapidly and accurately. Misread words were noted, but were found to occur with a low probability (mean $=.021$ ) and did not affect later identification performance.

Phase 2: Pretraining for time judgments. A trial began when the message "PRESS WHEN READY" appeared on the screen; the message remained there until the subject pressed the "initiate" button. After the buttonpress, the message was erased, and a warning signal, consisting of two short horizontal lines surrounding the location of the to-be-presented duration marker, appeared on the screen for $500 \mathrm{msec}$. The marker, a string of five characters (the letter $\mathrm{Z}$ ), was presented for $20,33,46$, or $59 \mathrm{msec}$. (These values were chosen such that, on average, the subjects were performing at about $50 \%$ correct, with $25 \%$ being chance.) The offset of the marker was immediately followed by a 1 -sec mask of five ampersands; the mask was presented in the same location as the marker. The subject was required to categorize each duration by pressing $1,2,3$, or 4 on the computer keyboard, with 1 denoting the briefest duration and 4 the longest. There were 100 trials, with each of the four durations occurring 25 times in a random order.

Phase 3: Practice. The 14 practice words were used to familiarize the subject with the perceptual identification task. A trial began with the subject's pressing the "initiate" button. The 500-msec warning signal appeared on the screen and was immediately followed by a 30 - or a 50 -msec word, which was immediately followed by the 1-sec mask. The subject was required to identify the word; guessing was encouraged. Verbal identification responses were recorded manually by the experimenter. Seven of the practice words were presented at $30 \mathrm{msec}$ and 7 at $50 \mathrm{msec}$, in a random order.

The 14 practice words were shown again, with the time-judgment task added to perceptual identification. Now, after having identified the word, the subject was required to categorize its duration using the four categories from Phase 2. The subject was not informed that there were only two stimulus durations. No feedback regarding perceptual identification or time judgment was provided.

Phase 4: Test. A second list of 80 words was constructed, consisting of one of the two sets of 40 words presented during study in Phase 1 (CRITICAL) and the set of 40 words not used during Phase 1 (NOVEL). Twenty CRITICAL and 20 NOVEL words were presented for $30 \mathrm{msec}$, and 20 CRITICAL and 20 NOVEL words were presented for $50 \mathrm{msec}$. The subject was required to identify each word and then to categorize its duration using the four categories from Phase 2 
As a result of counterbalancing the three sets of 40 words for item status, three different lists of 80 words each were used during this phase. For each of the three lists, the words were presented in seven different random orders.

\section{Results and Discussion}

The reported data are from Phase 4. Table 1 presents the perceptual identification results, averaged across subjects, in terms of the proportion of words correctly identified. As would be expected, presentation duration influenced identification performance, with more words being correctly identified at $50 \mathrm{msec}$ than at $30 \mathrm{msec}$. Words presented once prior to the perceptual identification task (CRITICAL) were more likely to be correctly identified than were words not presented in the earlier phase of the experiment (NOVEL). The Wilcoxon T test ${ }^{4}$ indicates that the perceptual enhancement of CRITICAL words occurred for both the $30-\mathrm{msec}[\mathrm{T}(21)=25$, $\mathrm{p}<.01]$ and the $50-\mathrm{msec}[\mathrm{T}(15)=1, \mathrm{p}<.01]$ presentation durations. As has been demonstrated in other studies (Jacoby, 1983a; Jacoby \& Dallas, 1981; Jacoby \& Witherspoon, 1982; Witherspoon, 1983), one prior presentation of a word enhances the perceptual identification of that word relative to words not presented previously, indicating that memory for a single prior presentation of a word affects its later perception.

The mean temporal category was determined for each subject, and this measure, averaged across subjects, is shown in Figure 1. Not surprisingly, the durations of 50msec words were judged to be longer than those of 30msec words $[\mathrm{T}(21)=0, \mathrm{p}<.01]$. Of greater interest are the findings that the durations of correctly identified words were judged to be longer than those of incorrectly identified words $[\mathrm{T}(21)=1, \mathrm{p}<.01]$ and that the durations of CRITICAL words were judged to be longer than those of NOVEL words $[\mathrm{T}(20)=16.5, \mathrm{p}<.01]$. These results agree with the spontaneous reports of subjects (Jacoby \& Dallas, 1981) that some words appear longer than others. The finding that the durations of words that were correctly identified were judged to be longer than the durations of words that were incorrectly identified supports the Jacoby and Dallas position that relative perceptual fluency results in a tendency to judge the presentation duration as being long. Since CRITICAL words are perceptually enhanced relative to NOVEL words, judgments of the durations of CRITICAL words as being longer than those of NOVEL words also support this position.

Figure 1 also reveals that, in general, the durations of CRITICAL words were judged to be longer than those

Table 1

Proportion of Words Correctly Identified in Experiment 1 for Each Word Type and Each Presentation Duration

\begin{tabular}{lccc} 
& \multicolumn{2}{c}{ Presentation Duration (in Milliseconds) } & \\
\cline { 2 - 3 } Word Type & 30 & 50 & Mean \\
\hline CRITICAL & .49 & .80 & .65 \\
NOVEL & .36 & .63 & .50 \\
Mean & .43 & .71 & \\
\hline
\end{tabular}

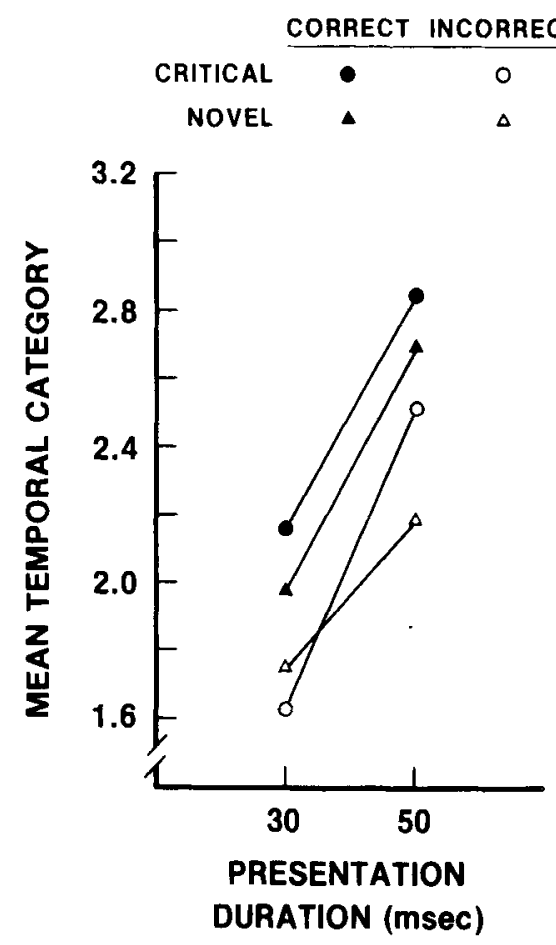

Figure 1. Mean temporal category for each word type, separately for correct and incorrect identifications, as a function of presentation duration in Experiment 1.

of NOVEL words for both correct and incorrect identifications. This pattern of duration judgments indicates that previously presented words are discriminated from novel words for both correct and incorrect identifications. In order to investigate this discrimination more fully, identification responses were categorized in terms of similarity to the stimulus word: omissions (no identification response), number of letters in common with the stimulus word regardless of order, (0-1, 2-3, and 4-5), and correct (all letters in common and in the correct position). Mean temporal category is plotted as a function of identification response type in Figure 2. For both CRITICAL and NOVEL words, the durations for omissions were judged to be much shorter than those for the other response types, and there was little difference in the judged durations of the two word types. For all the other response types, the durations of CRITICAL words were judged to be longer than those of NOVEL words. For both word types, judged duration increased as the identification response became more similar to the stimulus word. These patterns are clearer at the $50-\mathrm{msec}$ presentation than at the 30-msec presentation.

Overall, the data indicate that the more of the word identified, the longer the judged duration. This relationship supports the proposition that subjects misattribute relative perceptual fluency to longer presentation durations. The increase in perceptual fluency as more letters are correctly identified is misattributed to the word's being on the screen for a longer duration. The data also reveal that, even for equivalent response-stimulus similarity, the durations of CRITICAL words tended to be judged to be 


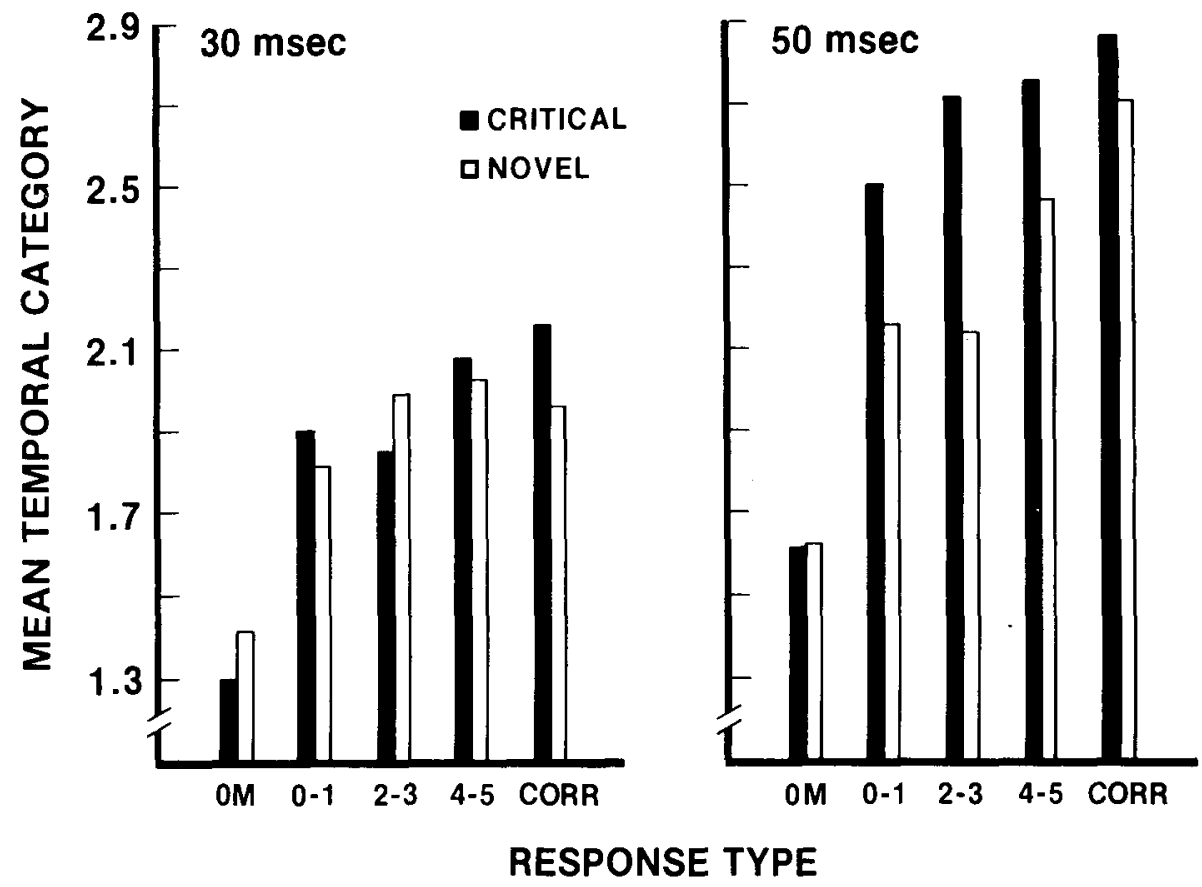

Figure 2. Mean temporal category for identification response types in Experiment 1.

longer than those of NOVEL words. The duration judgments demonstrate that previously presented words are distinguished from novel words even when the degree of similarity between identification response and stimulus word is the same. Thus, although duration judgments are related to response-stimulus similarity, they are also determined by whether the word has been presented previously.

The relatively shallow slope of the novel-incorrect function in Figure 1 deserves comment. It suggests poorer temporal discrimination for the novel-incorrect case than for the other three cases. This relationship is easier to see in a ROC plot, and Figure 3 presents the data in $\mathrm{Z}$ coordinates (see Green \& Swets, 1966). ${ }^{5}$ For each of the four cases-critical-correct, novel-correct, critical-incorrect, and novel-incorrect-there are three pairs of $P\left(R_{L} \mid L\right)$ and $P\left(R_{L} \mid S\right)$ values, where $P\left(R_{L} \mid L\right)$ denotes the probability of a "long" response to the long $(50-\mathrm{msec})$ duration and $\mathbf{P}\left(R_{L} \mid S\right)$ denotes the probability of a "long" response to the short ( $30-\mathrm{msec})$ duration. "Long"' is defined succes-

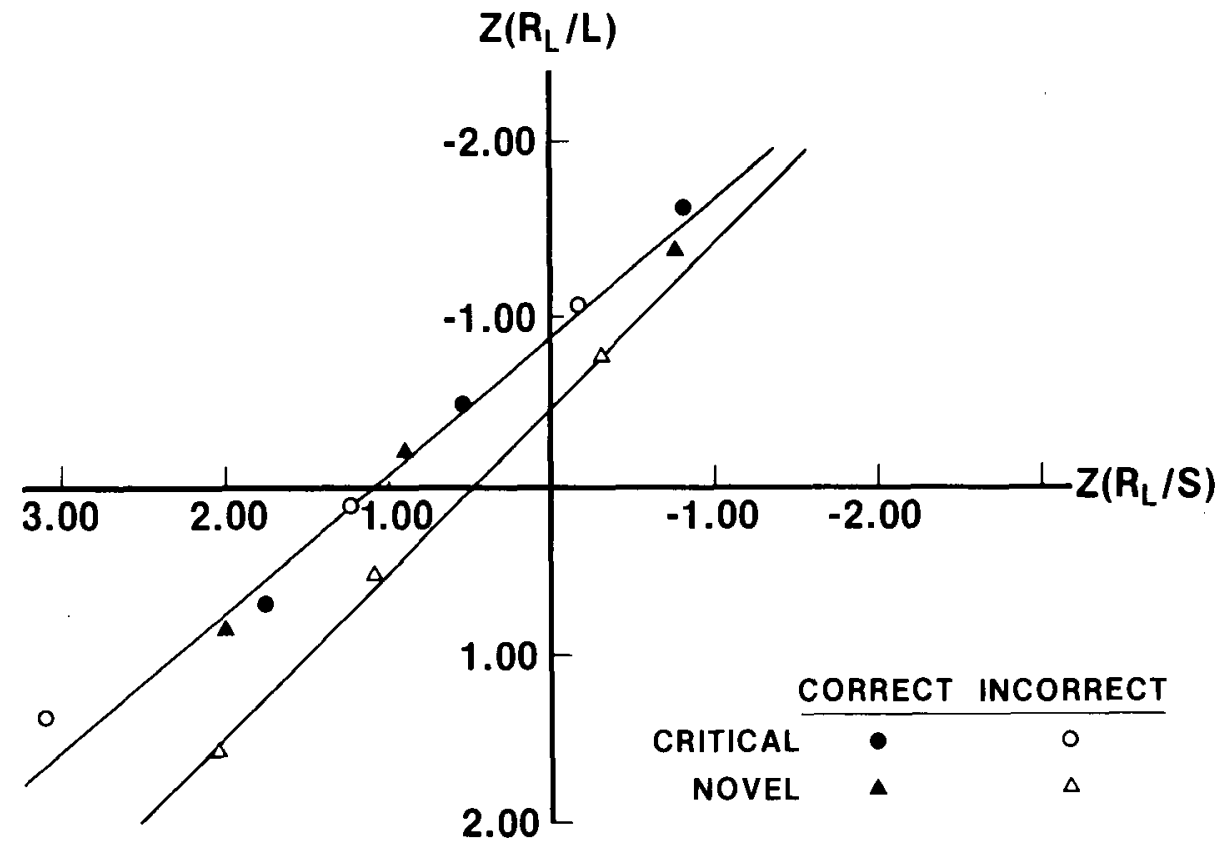

Figure 3. ROC plots in $\mathrm{Z}$ coordinates for Experiment 1. 
sively as Category 4 , Category 4 or 3 , Category 4 or 3 or 2 . That is, the criterion was successively relaxed so that more and more of the categories qualified for the longer-perceived-duration set. It is clear from Figure 3 that the three points for the novel-incorrect case fall below the nine points for the other three cases. Two lines were fit to the data: one line to the three novel-incorrect data points and one line to the remaining nine data points. In each case, the line minimized the sum of the squared perpendicular discrepancies. The value of $\mathrm{r}^{2}$ for the ninepoint line is .987 , suggesting equivalent discriminability between 30 and $50 \mathrm{msec}$ for critical-correct, novelcorrect, and critical-incorrect. The ordering of the data points along the line illustrates the pattern of performance revealed by the Wilcoxon test: More "long" responses were made to CRITICAL words than to NOVEL words and to correctly identified words than to incorrectly identified words. One interpretation of this ordering is that the expected value of the perceived-duration distribution is largest for durations marked by CRITICAL words that are correctly identified, smaller for NOVEL words that are correctly identified, and smallest for CRITICAL words that are not correctly identified. The finding of similar $\mathrm{d}^{\prime}$ values for these three cases indicates that, although the expected value is influenced, the variances of the perceived-duration distributions are not. Within the framework of this analysis, the lower $\mathrm{d}^{\prime}$ line for the novelincorrect case indicates reduced temporal discrimination between 30 and $50 \mathrm{msec}$ when the temporal intervals are marked by words that have not been presented previously and that are identified incorrectly. This result suggests that there is greater variability in the perceived-duration distribution when the duration is marked by a NOVEL word that is not correctly identified. ${ }^{6}$

The relationship between temporal resolution and identification response type is shown in Figure 4. For each identification response type, $d^{\prime}$ was determined for the three criterion values. (Since almost all omission responses were labeled Category 1 or 2 , only one d' value was determined for omissions.) The average $d^{\prime}$ over the three criteria is plotted in Figure 4 as a function of identification response type, separately for CRITICAL and NOVEL words. Overall, temporal discrimination is better when the duration is marked by a CRITICAL word than by a NOVEL word. For CRITICAL words, temporal discrimination is fairly constant across response types, except for omissions, for which it is relatively poor because most presentations, whether 30 or $50 \mathrm{msec}$, are labeled "short." For NOVEL words, discriminability improves as the identification response becomes more similar to the stimulus word, reaching the $d^{\prime}$ value for CRITICAL words when the identification is correct.

Cantor and Thomas (1977), Thomas and Cantor (1975, 1976, 1978), and Thomas and Weaver (1975) have presented a model that addresses the role of nontemporal information in the processing of brief temporal intervals. The model postulates that a stimulus of duration d, consisting of nontemporal information $\mathrm{I}$, is analyzed by a

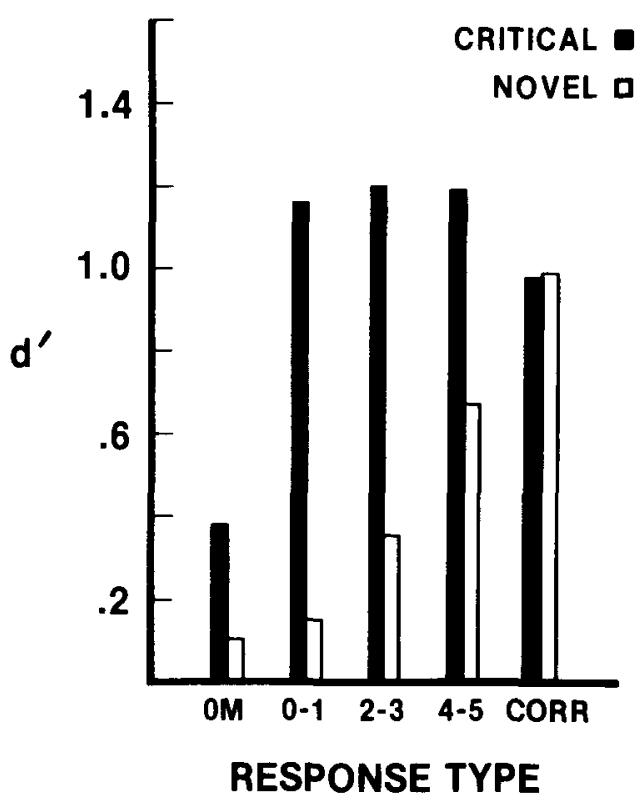

Figure 4. Average d' as a function of identification response type in Experiment 1.

timer and by an information processor. Attention is shared between the timer and the information processor, and the values and the reliability of the two outputs are functions of the amount of directed attention. When attention is directed at the information processor, the timer is less reliable in the sense of being less accurate and more variable. Applied to the present situation, the model suggests that less attention is needed by the information processor when a word is in memory, which leaves more attention for the timer, which results in less variability and therefore better temporal resolution for CRITICAL words than for NOVEL words. For NOVEL words, the amount of attention commanded by the information processor depends on ease of identification. Thus, as response-stimulus similarity increases, temporal resolution of intervals marked by NOVEL words increases.

In summary, the data from Experiment 1 show that one prior presentation influences perception as measured by perceptual identification, judged duration, and temporal discrimination. Previously presented words are more likely to be identified correctly than are novel words; the durations of previously presented words are judged to be longer than those of novel words for both correct and incorrect identifications; and temporal discriminations are better when durations are marked by previously presented words than by novel words. Although duration judgments and temporal discrimination are related to responsestimulus similarity, they are also determined by whether or not the word is in memory.

\section{EXPERIMENT 2}

Jacoby and Dallas (1981) and Witherspoon (1983) suggested that relative perceptual fluency results in a feeling of "familiarity" for previously presented words. This 
sense of "familiarity" then serves as one basis for distinguishing between old familiar items and new unfamiliar items. In Experiment 1, we showed that the durations of previously presented ("familiar') words were judged to be longer than those of new words. There are reports in the literature that the durations of familiar words, as defined by frequency of usage in Thorndike and Lorge (1944), are also judged to be longer than those of unfamiliar words in tachistoscopic identification tasks (e.g., Devane, 1974; Warm et al., 1964; Warm \& McCray, 1969). However, when familiarity was defined along a word-nonword dimension (e.g., Avant \& Lyman, 1975; Avant et al., 1975; Thomas \& Weaver, 1975), a different pattern of results was seen. Avant et al. (1975) and Avant and Lyman (1975) found that the durations of threeletter nonwords were judged to be longer than those of three-letter words, which were judged to be longer than those of single letters. That is, the durations of unfamiliar items were judged to be longer than those of familiar items. Thomas and Weaver (1975), however, found no difference in duration judgments between words and nonwords. The above groups of studies differed not only in the definition of the familiarity dimension, but also in the task requirement. In the studies conducted by Devane (1974), Warm et al. (1964), and Warm and McCray (1969) the subjects were required to identify the word and then to judge its duration, as they were in Experiment 1 here. In the other studies, the subjects were required only to judge duration. Miller (1977, as cited in Dember \& Warm, 1979) concluded that a positive relation between judged duration and familiarity, defined as approximation to English in his case, depends, in part, upon the requirement to process actively some aspect of the duration marker other than its duration per se. He found that the judged durations of letter strings increased with their approximation to English words when the subject was required to report the letters and to judge duration. In contrast, judged durations were independent of approximation to English when only duration judgments were required.

The purpose of Experiment 2 was to determine whether a prior presentation would influence duration judgments under conditions in which an identification response was not required. It is theoretically important to establish whether a prior presentation enhances perceptual fluency even when identification is not required by the task. Duration judgments, in the absence of an identification requirement, provide one method for doing so.

\section{Method}

\section{Subjects}

Twenty-one undergraduates enrolled in introductory psychology classes at McMaster University participated for course credit.

\section{Materials and Apparatus}

The materials and apparatus were the same as in Experiment 1.
Table 2

Mean Temporal Category in Experiment 2 for Each Word Type at Each Presentation Duration. (The Comparable Values from Experiment 1 are in Parentheses)

\begin{tabular}{lcc} 
& \multicolumn{2}{c}{ Presentation Duration (in Milliseconds) } \\
\cline { 2 - 3 } Word Type & 30 & 50 \\
\hline CRITICAL & $1.96(1.89)$ & $2.77(2.78)$ \\
NOVEL & $1.85(1.85)$ & $2.59(2.50)$ \\
\hline
\end{tabular}

\section{Procedure}

This experiment also consisted of four phases. Phases 1 and 2 were identical to those of Experiment 1. The first presentation of the 14 practice words in Phase 3, which in Experiment 1 required only identification responses, was omitted. During Phase 4, the subject was required only to make duration judgments.

\section{Results and Discussion}

The mean temporal category was determined for each subject; Table 2 presents this measure averaged across subjects. Table 2 also shows the comparable values from Experiment 1. As in Experiment 1, the durations of 50msec words were judged to be longer than those of 30msec words $[\mathrm{T}(21)=0, \mathrm{p}<.01]$. Of greater interest is the finding that the durations of CRITICAL words were judged to be longer than those of NOVEL words, both for the $30-\mathrm{msec}$ presentation $[\mathrm{T}(19)=40,<.05]$ and the 50-msec presentation $[\mathrm{T}(21)=50.5, \mathrm{p}<.05]$. A comparison of the values from the two experiments indicates that they are very similar, even though in Experiment 1 the subjects were required to identify the words, whereas in Experiment 2 they were not. These results indicate that one prior presentation influences duration judgments even in the absence of an identification requirement. It is clear that duration judgments provide a sensitive measure of memory of a prior presentation even in a situation in which there is no memory requirement imposed by the task.

Our results are different from those reported by Miller (1977, as cited in Dember \& Warm, 1979). When identification was not required, approximation to English had no influence on duration judgments, whereas one prior presentation did. Different definitions of "familiarity" yield different patterns of results.

\section{EXPERIMENT 3}

Feustel et al. (1983) addressed the issue of what is preserved in memory from a prior presentation. Data exist that indicate that, for some tasks, preservation in memory of the exact physical shape of the letters is not critical for perceptual enhancement. For example, changes in the physical appearance (case) of repeated items have little effect on perceptual enhancement (Feustel et al., 1983; Jacoby \& Witherspoon, 1982). Jacoby and Witherspoon (1982) reported that, although switching the presentation modality of words from auditory during study to 
visual during test virtually eliminated perceptual enhancement, the repetition effect was seen if the subjects were required to spell the auditorily presented words aloud during study. Further evidence that the repetition effect depends on more than physical characteristics of the stimulus word has been provided by Feustel et al. (1983), Murrell and Morton (1974), and Witherspoon (1982). These investigators did not find significant perceptual enhancement of words that were spelled similarly to previously presented words, but that bore no morphemic overlap. That is, there was no significant perceptual enhancement of a novel word that was perceptually similar to a previously presented word but that differed in meaning. If the presence of the word in memory was responsible for the results of the present experiment, then one would expect equivalent duration judgments of novel words that are perceptually similar to previously presented words and of novel words that are perceptually dissimilar from previously presented words, with the durations of both types of novel words being judged to be shorter than those of the previously presented words. Experiment 3 was conducted to explore this prediction.

Two sets of novel words were used. One set, PERCEPTUAL, consisted of words that were perceptually similar to the CRITICAL words. The words in the other set were similar to the NOVEL words in Experiment 1, in that they bore no systematic perceptual similarity to the CRITICAL words.

\section{Method}

\section{Subjects}

Twenty-four undergraduates enrolled in introductory psychology classes at McMaster University participated for course credit.

\section{Materials and Apparatus}

As in Experiment 1, there were 134 low-frequency words (most were nouns), and 14 were used as practice words. In the set of 120 nonpractice words, 48 PERCEPTUAL words were selected in pairs (24) according to the following criteria: (1) a word was to be exactly one letter different by position from its paired word (e.g., "blade"-"blaze"); and (2) it was to have two or fewer letters by position in common with any other word in the entire 134-word pool (e.g., "blade"'-"waxen"; "anvil"'."tense"). Twenty-four of the words were assigned to one set and their partners to another set, and the two sets were counterbalanced for item status: presented in study or presented in test. The 72 remaining words served as either CRITICAL or NOVEL. These words were selected pseudorandomly from Thorndike and Lorge (1944), with the only restriction being that noted above: two or fewer letters by position in common with any other word. These 72 words were assigned randomly to one of three sets ( 24 words each), and the three sets were counterbalanced for item status: presented in study and test, presented only in study, presented only in test. The apparatus was identical to that used in Experiment 1.

\section{Procedure}

This experiment also consisted of four phases. During the study phase, the list consisted of 72 words: one member from each of the 24 PERCEPTUAL pairs, and two of the three sets of 24 words. The list during test also consisted of 72 words: the paired members of the PERCEPTUAL words, one of the two sets of 24 words presented during study, and the set of 24 words not presented dur- ing study. Thus, there were 24 PERCEPTUAL words, 24 CRITICAL words, and 24 NOVEL words during test. Half the items from each word type were presented for $30 \mathrm{msec}$, and half for $50 \mathrm{msec}$.

As a result of counterbalancing, there were six different lists of 72 words: two subsets of PERCEPTUAL words and three subsets of other words. For each of the six lists, the words were presented in two different random orders.

\section{Results}

Table 3 presents the perceptual identification results in terms of the proportion of words correctly identified. The Friedman test indicates that the three distributions are not the same $[\operatorname{Fr}(24)=18.15, p<.005]$. For 19 of the 24 subjects $(79 \%)$, more CRITICAL than NOVEL words were identified correctly, and for 2 subjects, there was no difference $[\mathrm{T}(22)=20, \mathrm{p}<.01]$; for 20 subjects $(83 \%)$, more CRITICAL than PERCEPTUAL words were identified correctly, and for 2 subjects, there was no difference $[\mathrm{T}(22)=11.5, \mathrm{p}<.01]$. In contrast, there was little difference between PERCEPTUAL and NOVEL words, with 13 subjects ( $54 \%$ ) showing better identification of PERCEPTUAL than of NOVEL words and 1 subject showing no difference $[\mathrm{T}(23)=120, \mathrm{p}>.05]$. Thus, CRITICAL words were more likely to be identified correctly than either type of novel word, and the two types of novel words did not differ significantly. One presentation of a word during the study phase enhanced the perceptual identification of that word relative to the perceptual identification of words not presented for study, and identification performance on the novel words was independent of whether the words were perceptually similar to or perceptually dissimilar to the study words. This result is in agreement with the data reported by Feustel et al. (1983), Murrell and Morton (1974), and Witherspoon (1982).

Mean temporal category is plotted as a function of presentation duration in Figure 5. As in Experiment 1, the durations of 50 -msec words were judged to be longer than those of 30 -msec words $(T=0, p<.01)$, and the durations of correctly identified words were judged to be longer than those of incorrectly identified words $(T=1$, $\mathrm{p}<.01)$. The Friedman test indicates that the three distributions of temporal judgments for CRITICAL, NOVEL, and PERCEPTUAL words differed significantly $[\operatorname{Fr}(24)=9.90, p<.01]$. The durations of CRITICAL words were judged to be longer than those of both NOVEL words and PERCEPTUAL words $[\mathrm{T}(24)=52$,

Table 3

Proportion of Words Correctly Identified in Experiment 3 for Each Word Type and Each Presentation Duration

\begin{tabular}{lccc} 
& \multicolumn{2}{c}{ Presentation Duration (in Milliseconds) } & \\
Word Type & 30 & 50 & Mean \\
\hline CRITICAL & .48 & .81 & .65 \\
NOVEL & .38 & .65 & .52 \\
PERCEPTUAL & .39 & .68 & .54 \\
Mean & .42 & .71 & \\
\hline
\end{tabular}



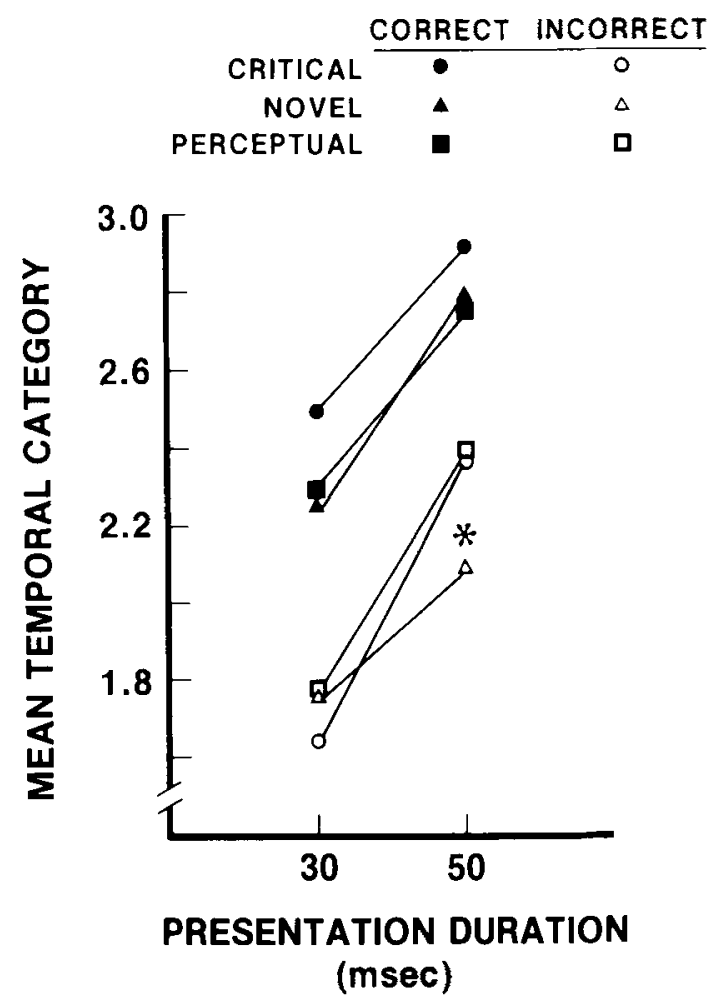

Figure 5. Mean temporal category for each word type, separately for correct and incorrect identifications, as a function of presentation duration in Experiment 3. The asterisk indicates mean temporal category for incorrectly identified PERCEPTUAL words with perceptual intrusions removed.

$\mathrm{p}<.01$, and $\mathrm{T}(23)=63.5, \mathrm{p}<.05$, respectively $]$, and the temporal judgments of the two types of novel words did not differ $[\mathrm{T}(23)=121, \mathrm{p}>.05]$.

Figure 5 also reveals that, for correct identifications, the durations of CRITICAL words were judged to be longer than those of both types of novel words at both stimulus durations. For incorrect identifications, there was little difference in temporal judgments among the three word types at $30 \mathrm{msec}$. At $50 \mathrm{msec}$, temporal judgments for CRITICAL and PERCEPTUAL words were similar and tended to be longer than the temporal judgments of NOVEL words. A comparison of Figure 5 with Figure 1 shows that the pattern of temporal judgments seen in Experiment 1 for CRITICAL and NOVEL words was replicated in Experiment 3. For correct identifications, the durations of CRITICAL words were judged to be longer than those of NOVEL words at both presentation durations, and for incorrect identifications, the durations of CRITICAL words were judged to be longer than those of NOVEL words at the longer $(50-\mathrm{msec})$ presentation. The additional finding in Experiment 3 is that, for correct identifications, temporal judgments of PERCEPTUAL words were similar to temporal judgments of NOVEL words, whereas, for incorrect identifications, temporal judgments of PERCEPTUAL words were similar to temporal judgments of CRITICAL words.
Table 4 presents mean temporal category for four error types: omissions, perceptual intrusions, study intrusions, and other errors. A "perceptual intrusion" is the identification of a novel perceptually similar word as the member of the PERCEPTUAL pair presented during study and therefore applies only to PERCEPTUAL words. For example, if "blade" were presented during study and "blaze" during test, a perceptual intrusion would be the identification response "blade" to the test word "blaze." A "study intrusion" refers to all other intrusion errors. That is, a study intrusion is the incorrect identification of a test word as a word that appeared during study. Table 4 shows that, as in Experiment 1, for each word type, the durations of omissions were judged to be shorter than those of the other error types. Study intrusions occurred infrequently for each word type, whereas perceptual intrusions accounted for $5 \%$ of errors at the 30 -msec presentation and $16 \%$ at the $50-\mathrm{msec}$ presentation. Mean temporal category was longer for perceptual intrusions than for the other error types. In fact, it was longer than the mean temporal category for correct judgments of CRITICAL words ( 2.50 and 2.92 for 30 - and 50 -msec presentations, respectively). The asterisk in Figure 5 represents the mean temporal category for PERCEPTUAL words when perceptual-intrusion errors are removed from the calculation. This value is similar to that for incorrectly identified NOVEL words. When perceptual intrusion errors are removed, temporal judgments of the two types of novel words are similar and are shorter than the temporal judgments of incorrectly identified CRITICAL words. When a PERCEPTUAL word is not identified correctly, there is a tendency, especially at the $50-\mathrm{msec}$ presentation, to identify the word as a word in memory. That is, information gained from the stimulus word appears to be combined with a memory bias that relies on retrieval of memory for prior episodes (Broadbent \& Broadbent, 1975; Jacoby, 1983a). Perceptual intrusions provide strong support for the view that the identification process is contacting memory left by prior presentation.

Table 4

Relative Frequency (P) of Four Error Types and Mean Temporal Category for Each Error Type Separately for Each Word Type at Each Presentation Duration: Experiment 3

\begin{tabular}{|c|c|c|c|c|c|c|c|}
\hline \multirow[b]{3}{*}{$\begin{array}{l}\text { Error } \\
\text { Type }\end{array}$} & \multirow{3}{*}{$\begin{array}{c}\text { Presentation } \\
\text { Duration } \\
\text { (in Milliseconds) }\end{array}$} & \multicolumn{6}{|c|}{ Word Type } \\
\hline & & \multicolumn{2}{|c|}{ CRITICAL } & \multicolumn{2}{|c|}{ NOVEL } & \multicolumn{2}{|c|}{ PERCEPTUAL } \\
\hline & & $P$ & Mean & $P$ & Mean & $\mathrm{P}$ & Mean \\
\hline \multirow[t]{2}{*}{ Omission } & 30 & .19 & 1.29 & .23 & 1.00 & .26 & 1.20 \\
\hline & 50 & .14 & 1.75 & .10 & 1.80 & .10 & 1.44 \\
\hline $\begin{array}{c}\text { Perceptual } \\
\text { intrusion }\end{array}$ & $\begin{array}{l}30 \\
50\end{array}$ & & & & & $\begin{array}{l}.05 \\
.16\end{array}$ & $\begin{array}{l}2.75 \\
3.13\end{array}$ \\
\hline \multirow{2}{*}{$\begin{array}{l}\text { Study } \\
\text { intrusion }\end{array}$} & 30 & .02 & 2.00 & .03 & 1.60 & .01 & 2.00 \\
\hline & 50 & .07 & 2.00 & .03 & 2.33 & .08 & 2.86 \\
\hline \multirow{2}{*}{$\begin{array}{l}\text { Other } \\
\text { errors }\end{array}$} & 30 & .79 & 1.79 & .74 & 2.00 & .68 & 1.96 \\
\hline & 50 & .79 & 2.43 & .87 & 2.23 & .66 & 2.25 \\
\hline
\end{tabular}




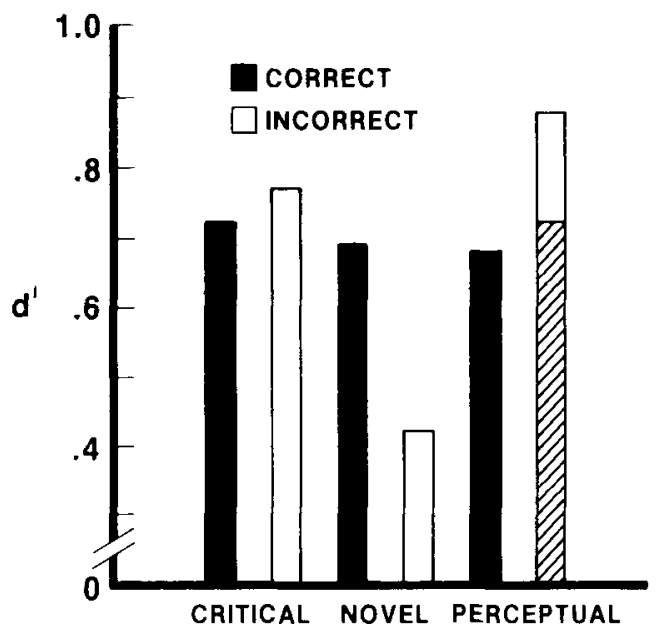

Figure 6. Average d' for each word type, separately for correct and incorrect identifications, in Experiment 3. The part with diagonal lines on the incorrect bar for PERCEPTUAL words represents $d^{\prime}$ when perceptual intrusions are removed.

For each word type, $d^{\prime}$ was determined for each of the three criterion values. The average $\mathrm{d}^{\prime}$ over the three criteria is shown in Figure 6 as a function of response type for each word type separately for correct and incorrect identifications. As in Experiment 1, temporal discrimination is poor when the durations are marked by NOVEL words that are not identified correctly. In contrast, temporal discrimination appears to be best when the new word is perceptually similar to a CRITICAL word and is identified incorrectly. However, removal of perceptual-intrusion errors (diagonal lines) reduces temporal discriminability for PERCEPTUAL words to the level obtained with CRITICAL words.

In summary, these data replicate the finding of others that a prior presentation of a word does not enhance the perceptual identification of a novel word that differs by one letter. That is, the availability of a perceptually similar word in memory does not result in perceptual enhancement. In general, duration judgments of the two types of new words are similar and are shorter than those of previously presented words. Exceptions are the temporal judgments for perceptual-intrusion errors. The duration of a novel word that is identified incorrectly as a similar, previously presented word tends to be judged as being relatively long.

\section{GENERAL DISCUSSION}

The data from the three experiments show that duration judgments are influenced by a prior presentation. The durations of previously presented words are judged to be longer than those of novel words even when the novel words differ by only one letter. The longer judgments for previously presented words are seen when the word types are equated for response-stimulus similarity and when an identification response is not required. The data support the hypothesis that the increase in perceptual fluency, resulting from a prior presentation, is misattributed to a longer presentation duration. Consistent with this misattribution hypothesis are the findings that the durations of omissions are judged to be shorter than those of other response types and that duration judgments increase with response-stimulus similarity.

A word in memory appears to be processed more readily than a novel word. Haber $(1965,1966)$, Haber and Hershenson (1965), Haber and Hillman (1966), and Hershenson and Haber (1965) have shown that repeated tachistoscopic presentations of the same word improved identification accuracy. Their task differed from ours in that their prior presentations were tachistoscopic, whereas ours were not. They argued that the improvement was not due to the accumulation of "partial information" and was not mediated by guessing, response selection, or other nonperceptual factors. They concluded that the effective variable was the clarity of the percept. For Haber and his colleagues, a word in memory appears to be clearer, and it is this increase in clarity that aids perceptual identification.

Weintraub and McNulty (1973) have questioned the clarity explanation of Haber and his colleagues. In their experiments, whereas identification accuracy increased with repetitions, rated clarity did not. They concluded that, since there was no concomitant improvement in perceptual clarity as identification improved across repetitions, perceptual clarity could not be the important factor underlying improved accuracy.

It is not clear from the literature why Haber and his colleagues obtained one pattern of results and Weintraub and McNulty (1973) another pattern. Given our results, an important next step is a series of experiments similar to those reported in this paper. However, the clarity of the display, rather than duration, would be varied during test, and subjects would be required to make clarity judgments, rather than duration judgments. We would expect a prior presentation to influence rated clarity. A CRITICAL word embedded in visual noise would be expected to be rated as being clearer than a NOVEL word embedded in less visual noise.

In the time-perception literature, much interest has focused on the influence of nontemporal variables on duration judgments (see Allan, 1979). It has been shown that the durations of loud tones are judged to be longer than those of soft tones, those of high-pitched tones to be longer than those of low-pitched tones, those of bright lights to be longer than those of dim lights, etc. In a recent set of articles, Gomez and Robertson (1979) and Robertson and Gomez (1980) suggested that when the stimulus set includes large and small objects, the large objects will be judged to be longer in duration than the small objects because both "large" and "long" are "more" of their respective dimensions, whereas both "small" and "short" are "less" of those dimensions. Subjects appear to attribute a particular mapping of one dimension onto the other, such that the high ends of both go together, as do the low ends of both: More goes with more, and 
less goes with less. This account of duration judgments is similar to ours in that it rests on an incorrect attribution. In the case of size, subjects incorrectly attribute a larger size to a longer presentation duration; in our experiments, the subjects incorrectly attributed increased perceptual fluency to a long presentation duration. In this sense, the misattribution hypothesis provides an explanation for the influence of various types of nontemporal variables on judged duration.

We noted earlier that Devane (1974), Warm et al. (1964), and Warm and McCray (1969) have reported that judged duration increased with familiarity as defined by the Thorndike and Lorge (1944) word count. These authors have provided an account of the relationship between judged duration and familiarity different from that which we provide. They have argued that, since familiar words were easier to identify than unfamiliar words, more time was available for processing duration information. According to their position, duration judgments are related to estimates of the time available to process the duration. This processing-time account is more restricted than the misattribution hypothesis in that it would not apply to other dimensions such as loudness, pitch, size, and brightness.

In her review of the time-perception literature, Allan (1979) noted that, whereas nontemporal variables usually influence judgments of duration, temporal discrimination is often invariant. In contrast, the signal detection analysis of the present data indicates that a prior presentation does influence temporal discrimination. It appears that when the duration is marked by an incorrectly identified word that is not in memory, temporal resolution is relatively difficult. It is as though the variance of the underlying perceptual-duration distribution is increased. Because of the small number of data points from individual subjects, the $d^{\prime}$ analyses in this paper were based on group data. Allan (1983) argued that quantitative psychophysical relationships should be evaluated on individual subject data and urged caution about conclusions based on group data. A task for the immediate future is to obtain sufficient data from individual subjects to allow a quantitative description of the relationship between prior presentation and temporal resolution.

Duration judgments have been shown to be a valuable dependent measure of memory in the perceptual identification task. They provide support for the position advanced by Feustel et al. (1983), Jacoby (1983a, 1983b), and Witherspoon (1983), that perception is influenced by memory for prior episodes. One prior presentation influences perception, as revealed by enhanced perceptual identification, longer duration judgments, and better temporal discrimination.

\section{REFERENCES}

Allan, L. G. (1979). The perception of time. Perception \& Psychophysics, 26, 340-354.

Allan, L. G. (1983). Magnitude estimation of temporal intervals. Perception \& Psychophysics, 33, 29-42.

Avant, L. L., \& Lyman, P. J. (1975). Stimulus familiarity modifies perceived duration in prerecognition visual processing. Journal of $E x$ perimental Psychology: Human Perception and Performance, 1, 205-213.

Avant, L. L., Lyman, P. J., \& ANTEs, J. R. (1975). Effects of stimulus familiarity upon judged visual duration. Perception \& Psychophysics, 17, 253-262.

Broadbent, D. E., \& Broadbent, M. H. P. (1975). Some further data concerning the word frequency effect. Journal of Experimental Psychology: General, 104, 297-308.

Cantor, N. E., \& Thomas, E. A. C. (1977). Control of attention in the processing of temporal and spatial information in complex visual patterns. Journal of Experimental Psychology: Human Perception and Performance, 3, 243-250.

DemBer, W. N., \& WARM, J. S. (1979). Psychology of perception. Holt, Rinehart \& Winston

Devane, J. R. (1974). Word characteristics and judged duration for two response sequences. Perceptual and Motor Skills, 38, 525-526.

Feustel, T. C., Shiffrin, R. M., \& Salasoo, A. (1983). Episodic and lexical contributions to the repetition effect in word identification. Journal of Experimental Psychology: General, 112, 309-346.

Gomez, L. M., \& RoBerTson, L. C. (1979). The filled-duration illusion: The function of temporal and nontemporal set. Perception \& Psychophysics, 25, 432-438.

Green, D. M., \& SWETS, J. A. (1966). Signal detection theory and psychophysics. New York: Wiley.

HaBER, R. N. (1965). The effect of prior knowledge of the stimulus upon word recognition processes. Journal of Experimental Psychol ogy, 69, 282-286.

HABER, R. N. (1966). Repetition as a determinant of perceptual recog nition processes. In J. C. Mott-Smith, W. Wathen-Dunn, H. Blum, \& P. Lieberman (Eds.), Symposium on models for the perception of speech and visual form. Cambridge, MA: MIT Press.

HABER, R. N., \& HERSHENSON, M. (1965). The effects of repeated brief exposures on growth of a percept. Journal of Experimental Psychology, 69, 40-46.

Haber, R. N., \& Hillman, E. R. (1966). The effect of repetition on the perception of single letters. Perception \& Psychophysics, 1 , 347-350.

Hershenson, M., \& HaBer, R. N. (1965). The role of meaning in the perception of briefly exposed words. Canadian Joumal of Psychology, 19, 42-46.

JACOBY, L. L. (1983a). Perceptual enhancement: Persistent effects of an experience. Journal of Experimental Psychology: Learning, Memory, and Cognition, 9, 21-83

JACOBY, L. L. (1983b). Remembering the data: Analyzing interactive processing in reading. Journal of Verbal Learning and Verbal Behavior, 22, 485-508.

JACOBY, L. L. (1984). Incidental vs. intentional retrieval: Remembering and awareness as separate issues. In N. Butters \& L. R. Squire (Eds.), The neuropsychology of memory. New York: Guilford Press.

JACOBY, L. L., \& DALLAS, M. (1981). On the relationship between autobiographical memory and perceptual learning. Joumal of Experimental Psychology: General, 3, 306-340.

JACOBY, L. L., \& WITHERSPOON, D. (1982). Remembering without awareness. Canadian Journal of Psychology, 36, 300-324.

MorTon, J. (1979). Facilitation in word recognition: Experiments causing change in the logogen model. In P. A. Kolers, M. E. Wrolstal, \& H. Bouma (Eds.), Processing of visible language (Vol. 1). New York: Plenum Press.

MurRell, G. A., \& MORToN, J. (1974). Word recognition and morphemic structure. Journal of Experimental Psychology, 102, 963-968.

Robertson, L. C., \& Gomez, L. M. (1980). Figural vs. configural effects in the filled duration illusion. Perception \& Psychophysics, 27, 111-116.

Thomas, E. A. C. \& Cantor, N. E. (1975). On the duality of simultaneous time and size perception. Perception \& Psychophysics, 18, 44-48.

Thomas, E. A. C., \& Cantor, N. E. (1976). Simultaneous time and size perception. Perception \& Psychophysics, 19, 353-360.

ThOMAS, E. A. C., \& CANTOR, N. E. (1978). Interdependence between the processing of temporal and nontemporal information. In J. Re- 
quin (Ed.), Attention and performance VII. Hillsdale, NJ: Erlbaum. Thomas, E. A. C., \& Weaver, W. B. (1975). Cognitive processing and time perception. Perception \& Psychophysics, 17, 363-367.

ThORNDIKE, E. L., \& LoRGE, I. (1944). The teacher's word book of 30,000 words. New York: Teacher's College Press, Columbia University.

Warm, J. S., Greenberg, L. F., \& Dube, C. S., II. (1964). Stimulus and motivational determinants in temporal perception. Journal of Psychology, 58, 243-248.

WARM, J. S., \& MCCRAY, R. E. (1969). Influence of word frequency and length on the apparent duration of tachistoscopic presentations. Journal of Experimental Psychology, 79, 56-58.

Weintraub, D. J., \& McNulty, J. A. (1973). Clarity versus indentifiability of repeatedly flashed patterns. Joumal of Experimental $P_{S y-}$ chology, 99, 293-305.

WITHERSPOON, D. (1982). Effects of physical similarity in words for perceptual identification. Unpublished manuscript, McMaster University, Hamilton, Ontario, Canada.

WITHERSPOON, D. (1983). The dissociation between tacit and reflective measures of memory. Unpublished doctoral dissertation, McMaster University, Hamilton, Ontario, Canada.

\section{NOTES}

1. We thank an anonymous referee for this example.

2. Experiment 1 was described in Witherspoon (1983), and the main result was noted by Jacoby and Witherspoon (1982).

3. We used a "scrolling" technique for tachistoscopic presentation of the words. The "PRESS WHEN READY" message, the warning signal, the word, and the mask were written on successive lines of the video screen prior to each trial. The "PRESS WHEN READY" message was visible in the presentation window; the remaining material was hidden by the black card. Upon trial initiation, each line was "scrolled" upward and was viewed successively through the presentation window.

The presentation duration and other intervals were approximate, due to the error introduced by the "refresh" cycle of the screen. Although this error adds variability to the results, it does not compromise them, since it is random.

4. We have used nonparametric statistics to analyze the data rather than violate the assumptions underlying such parametric tests as $t$ or ANOVA. We realize that, in some instances, our comparisons are nonindependent, but we are unaware of more appropriate nonparametric tests. The number of observations entering a particular test varies for two reasons. For the Wilcoxon test, tied observations are eliminated. In cases in which duration judgments are conditionalized on a dependent variable (number or correct or incorrect identifications), there are cells with no entries.

5. The ROC analysis is descriptive, not theoretical. It was performed on group data because there were insufficient data from individual subjects. We comment on the pitfalls of this approach later in the paper.

Perpendicular discrepancies are usually minimized in determining the best-fitting ROC curve in linear coordinates. The slope is the ratio of the standard deviation of the Z-transformed $P\left(R_{L} \mid L\right)$ values to the standard deviation of the $Z$-transformed $P\left(R_{L} \mid S\right)$ values.

6. One of the referees suggested that poorer temporal resolution for the novel-incorrect case might be an artifact of too few response categories. We note that this is not a plausible account within the framework of the signal detection analysis used. Of course, it may be consistent with a different model.

(Manuscript received January 12, 1984;

revision accepted for publication November 5, 1984.) 